\title{
Seasonal shifts in the solute ion ratios of vadose zone rock moisture from the Eel River Critical Zone Observatory
}

\author{
Jennifer L. Druhan ${ }^{1} \cdot$ Nicole Fernandez ${ }^{1} \cdot$ Jia Wang $^{1} \cdot$ William E. Dietrich ${ }^{2}$. \\ Daniella Rempe ${ }^{3}$
}

Received: 18 April 2017/Revised: 23 April 2017/Accepted: 23 April 2017/Published online: 5 May 2017

(C) The Author(s) 2017. This article is an open access publication

\begin{abstract}
One of the greatest challenges in critical zone studies is to document the moisture dynamics, water flux, and solute chemistry of the unsaturated, fractured and weathered bedrock that lies between the soil and groundwater table. The central impediment to quantifying this component of the subsurface is the difficulty associated with direct observations. Here, we report solute chemistry as a function of depth collected over a full year across the shale-derived vadose zone of the Eel River Critical Zone Observatory using a set of novel sub-horizontal wellbores, referred to as the vadose zone monitoring system. The results of this first geochemical glimpse into the deep vadose zone indicate a dynamic temporal and depth-resolved structure. Major cation concentrations reflect seasonal changes in precipitation and water saturation, and normalized ratios span the full range of values reported for the world's largest rivers.
\end{abstract}

Keywords Vadose zone $\cdot$ Solute ion ratios $\cdot$ Critical Zone Observatory $\cdot$ Seasonal solute dynamics

11th International Symposium on Geochemistry of the Earth's Surface.

Jennifer L. Druhan

jdruhan@illinois.edu

1 Department of Geology, University of Illinois Urbana Champaign, Champaign, IL, USA

2 Department of Earth and Planetary Science, University of California Berkeley, Berkeley, CA, USA

3 Jackson School of Geosciences, University of Texas at Austin, Austin, TX, USA

\section{Introduction}

In uplands, such as those found across the western continental United States, hydrologic recharge predominantly occurs through large sections of unsaturated, weathered bedrock - the deep vadose zone (DVZ) - that act as a physical boundary between soils and aquifers. The biologically-mediated pathways by which solutes are generated, transported and transformed across the unique hydrologic regime of the DVZ are largely unknown. This uncertainty is compounded where DVZs are derived from lithology that naturally contains high organic carbon content, such as shales, in that the weathering reactions that drive DVZ formation also contribute to the stability and transformation of subsurface carbon. This linkage is currently uncharacterized, and given the substantial reservoir of subsurface carbon stored above the saturated water table (Piao et al. 2013), presents a critical knowledge gap limiting predictive understanding of terrestrial system response to a changing hydrologic cycle (Luo et al. 2016).

Weathering dynamics in the DVZ are distinct from those observed in shallow soil horizons and saturated aquifers. There is a unique combination of disparate biogeochemical timescales that occur in the DVZ, ranging from rapid rates of labile organic carbon decomposition to geologic rates of regolith development (Riebe et al. 2017). This merging is linked to the distribution of fluid residence times that result from the dual-domain structure of the DVZ (Rimon et al. 2011), thus producing chemical signatures that represent mixing over a broad range of timescales (Aarão Reis and Brantley 2017; Brantley and Lebedeva 2011). A recent study utilizing samples from the Eel River Critical Zone Observatory (ERCZO) in Mendocino County, California, United States, documented seasonal fluctuations in stream and groundwater major ion concentrations which support the 
hypothesis that groundwater chemistry regulates the observed concentration-discharge relationship (Kim et al. 2017). The extent to which the chemical signature of this groundwater reflects geochemical weathering in the DVZ is unknown. Here, we report the first direct evidence of solute chemistry evolution in the partially saturated, weathered shale DVZ of the ERCZO using a novel Vadose Monitoring System (VMS).

\section{Site description}

The intensively instrumented "Rivendell" hillslope (Fig. 1) of the ERCZO is underlain by Eocene Age Coastal Belt shales (and minor sandstone) of the Franciscan complex and drains to the US Geological Survey Hydrologic Benchmark river, Elder Creek $\left(16.8 \mathrm{~km}^{2}\right)$, a tributary of the $9500 \mathrm{~km}^{2}$ Eel River. The land emerged from the ocean about 4 million years ago and is sufficiently south and low elevation that it has not experience glaciation or periglacial processes. It lies in a Mediterranean climate with daily average temperatures ranging from 0 to $20^{\circ} \mathrm{C}$, and average annual precipitation and runoff of 1800 and $1303 \mathrm{~mm}$, respectively. There are nearly 6 months of little to no rain. A mixed evergreen old-growth forest of Douglas fir (some $>60 \mathrm{~m}$ tall), oaks and other broadleaf trees mantle the Rivendell hillslope, which has a mean gradient of $32^{\circ}$. Soils along this hillslope are thin $(<50 \mathrm{~cm})$, gravely and well-drained silt loam and loam inceptisols. Beneath the soil lies a variably weathered and fractured bedrock zone that ranges in depth to fresh bedrock from about $4 \mathrm{~m}$ near the channel to about $25 \mathrm{~m}$ at the hillslope divide. All runoff occurs via vertical unsaturated flow through the weathered bedrock to groundwater, which is perched on the fresh bedrock, and drains laterally to the channel. Neutron probe surveys have revealed three distinct hydrologic zones in the weathered bedrock: an upper zone that remains unsaturated (varying in thickness from a few meters to $18 \mathrm{~m}$ upslope), a zone that seasonally saturates, and a thin deep zone that remains saturated (Rempe 2016).

\section{Methods}

The VMS was installed in October of 2015 and is comprised of two flexible sleeves lined with water and gas sampling ports and water content sensors along a $55^{\circ}$ incline (Fig. 1). The ports and sensors were forced to be in direct contact with the unsaturated, fractured shale regolith by infilling the sleeves with cement, and the attached tubing and cables are routed to the surface through the interior of the sleeves. Three distinct types of sample ports are utilized, one which directly drains matrix water held in the weathered shale (suction lysimeter), one which samples freely draining water moving through the fracture network (passive lysimeter), and one with gas sample ports. Fluid samples are routinely analyzed for major and trace ion chemistry, stable water isotopes, and both fluid and gas phase (in)organic carbon.

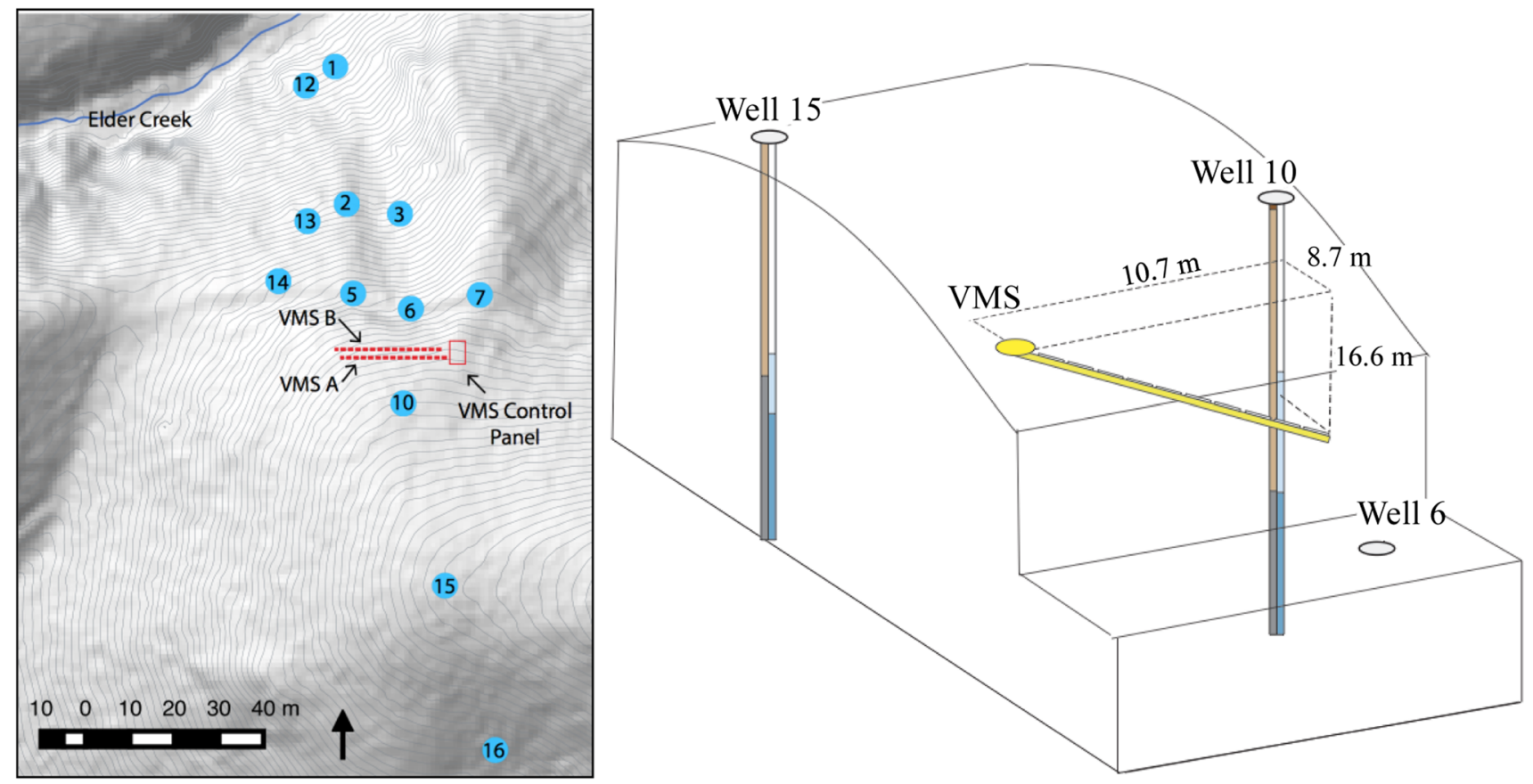

Fig. 1 Left panel 1 m elevation contours illustrating the instrumented Eel River CZO hillslope. Blue circles indicate numbered well bores. Two red dashed lines illustrate the direction in which the VMS system is installed. Right panel a depiction of the VMS (yellow line) drilled subhorizontally into the hillslope and instrumented using down-hole flexible sleeves 
Major and trace cation concentrations have been analyzed by quadrupole inductively coupled plasma mass spectrometry (ICP-MS) at the University of Illinois Urbana Champaign, using a Thermo Scientific iCAP Q tuned in standard mode with a quartz cyclonic spray chamber, PFAST nebulizer, quartz torch and ESI auto-sampler. Concentrations were calibrated against a multi-element standard and accuracy quantified against a freshwater sample standard provided by the Illinois State Water Survey using sample bracketing. The $2 \sigma$ external reproducibility was better than $\pm 5 \%$ for major elements.

\section{Results}

Preliminary measurements of major cation concentrations demonstrate clear seasonal variations across the ERCZO DVZ (Fig. 2). Data are presented as molar concentrations normalized to a common solute, here both magnesium and calcium are normalized to sodium. These normalizations serve several purposes (Sect. 5) but fundamentally allow comparison of solute chemical characteristics across a range of absolute concentrations independent of the effects of dilution and evaporation (Gaillardet et al. 1999). This is necessary in the VMS data, as the concentration of solutes fluctuate substantially between the wet and dry seasons.

\section{Discussion}

Normalized ratios fluctuate over at least two orders of magnitude and show clear seasonal differentiation. Fluids collected during the winter, wet season starting in February of 2016 have both low $\mathrm{Ca} / \mathrm{Na}$ and $\mathrm{Mg} / \mathrm{Na}$ ratios, approaching the average value of precipitation collected at the field site. These ratios increase through the year into the dry season before returning to low values in October and November. Representative elemental ratios taken from rivers draining exclusively silicate and carbonate lithology are shown for reference (Gaillardet et al. 1999). Kim et al. (2014) previously hypothesized that water entering the vadose zone quickly reacts with the regolith, resulting in increased solute concentrations. This reactivity is driven by the $\mathrm{pCO}_{2}$ of infiltrating rainwater, and thus the rate at which water moves through the vadose zone relative to the rate at which it reacts with the solid phase dictates the depth into the subsurface that the fluid reaches before equilibrating (and thus no longer driving chemical weathering). These data indicate that the solute ion ratios shift further from the initial rainwater values during the late spring and early summer dry period. Notably these high ratios do not appear in the groundwater, which suggests that the water recharging the perched aquifer generally moves quickly through the vadose zone, thus maintaining reactive potential across the partially-saturated depth profile.

These preliminary observations offer a unique glimpse into the seasonally transient geochemical composition that the DVZ imparts to infiltrating water. Notably, normalized concentration ratios with respect to sodium span the full range of values previously reported for the world's largest rivers (Gaillardet et al. 1999). Thus, the unique window into the partially saturated subsurface offered by the VMS illustrates the importance of this oxygenated, reactive regolith in determining the geochemical signature of fluids draining terrestrial landscapes.
Fig. 2 Calcium and magnesium normalized to sodium concentrations measured in all depths of the VMS with representative silicate and carbonate endmembers (Gaillardet et al. 1999) illustrated. Ion ratios for average rainwater collected at the site, and groundwater measured in wells 1,3 , and 10 at high flow and low flow rates are taken from Kim et al. (2014). Data are colored based on the sampling date, and span a range of time from February to November of 2016

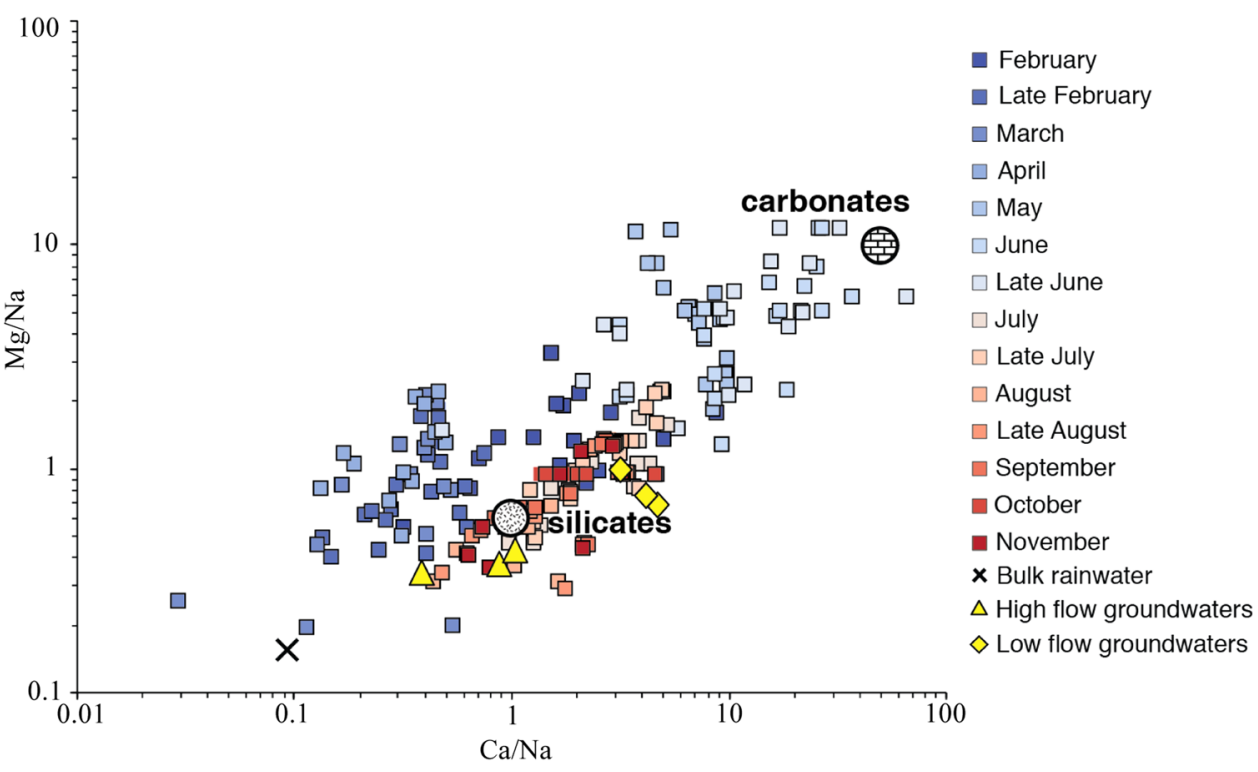


Acknowledgements This work was supported by the US National Science Foundation, Project EAR-1331904 for the Eel River Critical Zone Observatory.

\section{Compliance with ethical standards}

Conflict of interest On behalf of all authors, the corresponding author states that there is no conflict of interest

Open Access This article is distributed under the terms of the Creative Commons Attribution 4.0 International License (http://crea tivecommons.org/licenses/by/4.0/), which permits unrestricted use, distribution, and reproduction in any medium, provided you give appropriate credit to the original author(s) and the source, provide a link to the Creative Commons license, and indicate if changes were made.

\section{References}

Aarão Reis FDA, Brantley SL (2017) Models of transport and reaction describing weathering of fractured rock with mobile and immobile water. J Geophys Res Earth Surf. doi:10.1002/ $2016 \mathrm{jF} 004118$ (in press)

Brantley SL, Lebedeva MI (2011) Learning to read the chemistry of regolith to understand the critical zone. Ann Rev Earth and Planet Sci 39:387-416

Gaillardet J, Dupé B, Louvat P, Allègre CJ (1999) Global Silicate weathering and $\mathrm{CO}_{2}$ consumption rates deduced from the chemistry of large rivers. Chem Geol 159:3-30

Kim H, Bishop JKB, Dietrich WE, Fung IY (2014) Process dominance shift in solute water chemistry as revealed by longterm high-frequency water chemistry observations of groundwater flowing through weathered argillite underlying a steep forested hillslope. Geochim Cosmochim Acta 140:1-19
Kim H, Dietrich WE, Thurnhoffer BJ, Bishop JK, Fung IY (2017) Controls on solute concentration-discharge relationships revealed by simultaneous hydrochemistry observations of hillslope runoff and stream flow: the importance of critical zone structure. Water Resour Res 53:1424-1443

Luo YQ, Ahlstrom A, Allison SD, Batjes NH, Brovkin V, Carvalhais $\mathrm{N}$, Chappell A, Ciais P, Davidson EA, Finzi AC, Georgiou K, Guenet B, Hararuk O, Harden JW, He YJ, Hopkins F, Jiang LF, Koven C, Jackson RB, Jones CD, Lara MJ, Liang JY, McGuire AD, Parton W, Peng CH, Randerson JT, Salazar A, Sierra CA, Smith MJ, Tian HQ, Todd-Brown KEO, Torn M, van Groenigen KJ, Wang YP, West TO, Wei YX, Wieder WR, Xia JY, Xu X, $\mathrm{Xu}$ XF, Zhou T (2016) Toward more realistic projections of soil carbon dynamics by Earth system models. Glob Biogeochem Cycles 30:40-56

Piao S, Sitch S, Ciais P, Friedlingstein P, Peylin P, Wang X, Ahlström A, Anav A, Canadell JG, Cong N, Huntingford C, Jung M, Levis S, Levy PE, Li J, Lin X, Lomas MR, Lu M, Luo Y, Ma Y, Myneni RB, Poulter B, Sun Z, Wang T, Viovy N, Zaehle S, Zeng N (2013) Evaluation of terrestrial carbon cycle models for their response to climate variability and to $\mathrm{CO}_{2}$ trends. Glob Change Biol 19:2117-2132. doi:10.1111/gcb. 12187

Rempe DM (2016) Controls on critical zone thickness and hydrologic dynamics at the hillslope scale. Doctoral dissertation, UC Berkeley. http://escholarship.org/uc/item/6td3h4s8

Riebe CS, Hahm J, Brantley SL (2017) Controls on deep critical zone architecture: a historical review and four testable hypotheses. Earth Surf Proc Land 42(1):128-156. doi:10.1002/ esp. 4052

Rimon Y, Nativ R, Dahan O (2011) Physical and chemical evidence for pore-scale dual-domain flow in the vadose zone. Vadose Zone J 10(1):322-331 